\title{
Development of a 14-inch ID High-Pressure Hybrid Riser for SBOP Drilling
}

\author{
E. Persent, J. Guesnon, J.-M. Leroy, F. Richard and E. Laval \\ Institut français du pétrole, IFP, 1-4 avenue de Bois-Préau, 92852 Rueil-Malmaison Cedex - France \\ e-mail: emmanuel.persent@ifp.fr - jean.guesnon@ifp.fr - j-marc.leroy@ifp.fr - florence.richard@ifp.fr - emmanuel.laval@ifp.fr
}

\begin{abstract}
Résumé - Développement d'un riser hybride 14'ID haute pression pour le forage SBOP Cet article présente le développement d'un riser hybride 14"ID haute pression (10000 psi) pour le forage en offshore ultra profond (10000 ft) avec BOP en surface. Ce système mécanique est obtenu en adaptant et combinant deux technologies préexistantes, développées par l'IFP pour d'autres applications :

- les connecteurs Clip, comportant une double rangée de dentures alternées pour procurer un moyen de connexion sûr et rapide des éléments de riser;

- les tubes hybrides, obtenus par frettage circonférentiel de tubes en acier au moyen de rubans constitués de fibres de carbone imprégnées d'une résine polyamide thermoplastique.
\end{abstract}

L'IFP a développé un nouveau connecteur Clip de 355,6 mm (14") de diamètre intérieur pour l'application au riser hybride haute pression. Ce connecteur est capable de supporter une tension axiale de 1270 t et une pression opératoire de 690 bar. Par ailleurs, un tube hybride de 406,4 mm (16") de diamètre extérieur nominal a été dimensionné pour remplacer le tube riser en acier conventionnel par un tube fretté d'épaisseur plus faible, donc plus léger. Le gain de poids significatif ainsi obtenu permet de concevoir un système riser capable de supporter les spécifications de tenue aux fortes pressions et aux grandes profondeurs d'eau.

Suite à des études de conception et de dimensionnement, un ensemble prototype de diamètre intérieur 14" a été fabriqué, consistant en deux sections de riser hybride jointes par un connecteur Clip haute pression. Un programme de tests incluant des essais d'éclatement en pression interne et d'écrasement en pression externe, ainsi que des essais de fatigue en traction axiale cyclique, a été défini et réalisé pour qualifier les performances du connecteur Clip et des tubes hybrides. La réalisation d'essais de fatigue complémentaires des tubes hybrides et le test sur champ d'un élément de riser prototype à échelle 1 devraient être les prochaines étapes du projet.

$\mathrm{Au}$ stade actuel, les résultats des essais (éclatement, collapse, fatigue) confirment que les connecteurs Clip et les tubes hybrides sont des technologies bien adaptées pour le forage en offshore ultra profond avec BOP en surface. Toutefois, la tenue en fatigue des tubes hybrides requiert encore une qualification plus approfondie.

\footnotetext{
Abstract - Development of a 14-inch ID High-Pressure Hybrid Riser for SBOP Drilling - This paper discusses the development of a 14-inch ID high-pressure hybrid riser (10000 psi) for surface BOP drilling in ultra-deep water (10000 ft). The high-pressure hybrid riser system is obtained by adapting and combining two existing technologies, previously developed by the IFP for other applications:

- the Clip connector, a double breech-block type connector to provide a quick and safe connection for riser joints;

- hybrid pipe technology, a steel pipe hoop-wound with tapes of carbon fibers impregnated with polyamide thermoplastic resin.
} 
IFP has developed a new 14-inch ID HP Clip connector for the hybrid riser application. The connector is capable of withstanding a 2.8 million pound tension and a 10000 psi operating pressure. In addition, a 16-inch nominal $O D$ hybrid riser pipe has been designed to replace the steel riser pipe with a thinnerwalled hoop-wound steel pipe. The significant weight savings that can be achieved with the hybrid riser pipe make it possible to design an effective riser architecture to withstand the high pressure and deep water requirements.

Pursuant to design studies, a 14-inch ID prototype assembly consisting of two hybrid riser pipe sections with a high-pressure Clip connector was manufactured. A test program, including burst and collapse tests as well as cyclic fatigue testing, was formulated and carried out to qualify the performance of the Clip connector and hybrid riser pipe system. Completion of hybrid pipe additional fatigue testing and realization of a scale-one field testing of the hybrid riser are considered as the next steps of the project.

To date, the main test results (burst, collapse, fatigue resistance) confirm that the Clip connector and the hybrid pipe technologies are well suited for ultra-deep sea drilling with a surface BOP. However, the fatigue resistance of hybrid riser pipes still needs to be better characterized.

\section{NOMENCLATURE}

$C_{f} \quad$ Coefficient

$P_{e} \quad$ External pressure

$P_{i} \quad$ Internal pressure

$S_{b r} \quad$ Bearing stress

$S_{e} \quad$ External area

$S_{i} \quad$ Internal area

$S_{l m} \quad$ Local membrane stress

$S_{p b} \quad$ Primary bending stress

$S_{p m} \quad$ General primary membrane stress

$S_{s e} \quad$ Secondary stress

$S_{s h} \quad$ Pure shear stress

$S_{u} \quad$ Ultimate tensile strength

$S_{y} \quad$ Yield strength

$\sigma_{C C} \quad$ Circumferential stress

$\sigma_{V M}$ Von Mises stress

$T_{b m} \quad$ Bending equivalent tension

$T_{\text {eff }}$ Effective tension

$T_{\text {tot }}$ Total tension

$T_{w} \quad$ Intended life

\section{INTRODUCTION}

The 14-inch ID high-pressure drilling riser was specifically designed for drilling operation with new technologies that are being developed for deep water exploration and production such as surface BOP drilling and completion from floating vessels or floating production units. Reference [1] presents a SBOP drilling operation offshore Brazil performed by SIEP. The authors discuss some of the key issues which had to be addressed, including rig modifications and operating procedures. References [2] and [3] give some guidelines for SBOP drilling operations.

After an initial review of existing and emerging qualified technologies, it was determined that the development of the high-pressure drilling riser could benefit from adapting and combining two recently field-proven technologies used for other applications:

- the Clip connector, a double breech-block type connector providing efficient and safe connection of riser joints;

- hybrid pipe technology, a hybrid pipe made of a steel core, hoop-wound with a strip of carbon fibers impregnated with a polyamide thermoplastic resin.

Both technologies were developed by the IFP. The practical benefits of the resulting riser system include: light weight, simple and robust design, fast make-up and breakout, and easy to maintain offshore.

The proposed 14-inch ID riser design was based on the stringent requirement of drilling in $10000 \mathrm{ft}$ water depth in the Gulf of Mexico conditions with 10000 psi well control pressure in the riser.

This paper presents the design features of the Clip connector, high-pressure drilling riser system and the tests that were performed to validate the design.

\section{HIGH-PRESSURE RISER DESIGN}

\subsection{Riser Specifications}

The riser specifications were developed for Surface BOP drilling and completion operations for floaters in ultra-deep waters:

- water depth: $10000 \mathrm{ft}$ (3048 m);

- maximum annulus surface pressure: 10000 psi (690 bars);

- minimum inside diameter: 14 inch for drilling and completion operations with any suitable 13-5/8 inch downhole tools;

- torque-resistant to be deployed from a Dynamically Positioned (DP) vessel;

- fast make-up (for operation efficiency) using simple tooling; 
- capability of pressure testing individual connection when required;

- robustness for drill floor operations;

- numerous make and break of the connections.

The system is a high-pressure drilling riser with a surface BOP and, therefore, without choke, kill or hydraulic peripheral lines. The drilling riser is made up of three main parts:

- the connection with the drilling rig consists of a tensioner system with a telescopic joint, a BOP and a transition joint;

- the riser string;

- the connection with the wellhead by means of a transition joint and a Seabed Isolation Device (SID).

In order to resist the high internal pressure, the riser pipe may be made of steel with heavy wall thickness or made with more advanced materials such as composite or steel/composite (hybrid) materials.

The IFP has developed a 16-inch nominal OD highpressure hybrid riser pipe able to withstand a 10000 psi operating pressure. This innovative technology leads to the following improvements in riser characteristics, which enable it to be used to extend the operating water depth of existing deepwater rigs:

- reduction of the mass of the riser;

- reduction of deckload and required tensioning capacity;

- reduction of the mud and storage volume (compared with using conventional marine riser systems).

The riser joint can be made neutrally buoyant with the addition of small-diameter buoyancy modules. In such a case, a 10000 -ft-long riser will require the same tension, volume and deck load as a 3300-ft marine drilling riser.

\subsection{Riser Analysis}

A global riser analysis was performed to determine the design load and specify the riser architecture. We selected the severe case of SBOP drilling in the Gulf of Mexico from a typical semi-submersible drilling vessel. Seven operating cases were taken into account for the design of the riser and the connector (Tab. 1).

There is as yet no API standard that can be used to guide the design of high-pressure drilling risers. API RP 16Q [4] is intended for conventional drilling riser design and operation. API Spec 16R [5] indicates the rules to be followed for designing riser connectors but does not take into account the features of high-pressure connectors. API RP 2RD [6], which is dedicated to FPS riser systems, may be used to select the acceptance criteria on stresses according to the operational situation (normal, extreme, survival). The design case factors per API are indicated in Table 1.

Dynamic calculations were performed with the DeepLines ${ }^{\circledast}$ software for each operating case and for three environmental conditions $(S, L \& H)$. Reference [7] gives information on this finite element code dedicated to static and dynamic analysis of riser systems. DeepLines was certified by Bureau Veritas in 2000. The validation is continuously enhanced by comparisons with model tests, in situ measurements or theoretical benchmarks gathered in the framework of projects or JIPs [8]:

- $S$ : Storm conditions (1-year, 5-year or 10-year winter storm conditions according to the considered operational cases) and corresponding current profiles;

- L: Loop conditions (1-year, 5-year or 25-year loop current profiles according to the considered operational cases) and corresponding wave conditions;

- $H$ : Hurricane conditions (1-year) for riser free-hanging.

Effective tension, bending moment, vertical angle and displacement were calculated along the riser. The worst case appears to be at the top connector (between the transition joint and the first riser joint) during well control (whatever the operational and environmental conditions), particularly if high top tension was applied to the riser.

TABLE 1

Loading cases for the design of the riser

\begin{tabular}{|c|c|c|c|c|c|c|c|c|c|}
\hline \multirow{2}{*}{ Case } & \multirow{2}{*}{ Category } & \multirow{2}{*}{$\begin{array}{l}\text { Operating } \\
\text { Condition }\end{array}$} & \multirow{2}{*}{$\begin{array}{c}\text { MASP* } \\
(\mathrm{psi})\end{array}$} & \multirow{2}{*}{$\begin{array}{l}\text { Inside } \\
\text { fluid }\end{array}$} & \multirow{2}{*}{$\begin{array}{l}\text { Mud } \\
\text { (ppg) }\end{array}$} & \multicolumn{2}{|c|}{ Environment } & \multirow{2}{*}{ Offset } & \multirow{2}{*}{$\begin{array}{c}\text { Coef. API } \\
\text { 2RD }\end{array}$} \\
\hline & & & & & & $S$ & $L$ & & \\
\hline 1 & Normal & Drilling & 0 & mud & 13 & $5 \mathrm{yr}$ winter & $5 \mathrm{yr}$ loop & $2 \%$ & 1.0 \\
\hline 2 & Extreme & Well control & 10000 & gas & 2.7 & $5 \mathrm{yr}$ winter & 5 yr loop & $2 \%$ & 1.2 \\
\hline 3 & Extreme & Non-drilling & 0 & mud & 13 & $10 \mathrm{yr}$ winter & 25 yr loop & $2 \%$ & 1.2 \\
\hline 4 & Survival & Non-drilling & 0 & mud & 13 & $10 \mathrm{yr}$ winter & $25 \mathrm{yr}$ loop & $4 \%$ & 1.5 \\
\hline 5 & Survival & Well control & 10000 & gas & 2.7 & $10 \mathrm{yr}$ winter & 25 yr loop & $4 \%$ & 1.5 \\
\hline 6 & Survival & Free-hanging & 0 & sea water & 8.56 & $10 \mathrm{yr}$ winter & $1 \mathrm{yr}$ hurricane & & 1.5 \\
\hline 7 & Normal & Pressure testing & 10000 & sea water & 8.56 & & $1 \mathrm{yr}$ loop & & 1.35 \\
\hline
\end{tabular}

*MASP: Maximum Anticipated Surface Pressure. 
In the Clip connector design, bending is translated into a load on the surface of the lugs and, therefore, was considered as an additional tension (true on the concave side of the riser). Design loads for the connector were deducted from the riser analysis using the following formula:

$$
T_{\text {tot }}=T_{\text {eff }}+P_{i} S_{i}-P_{e} S_{e}+T_{b m}
$$

As a result of this analysis, the tensile load for the design of the connector was set at 2800 kips according to the API Spec 16R methodology with two modifications due to the high-pressure environment:

- local pressure effect $\left(P_{i}, P_{e}\right)$ on all surfaces of the connector must be added to the tension to complete the loading conditions;

- allowable stresses will be multiplied by a coefficient, $C_{f}$, depending on the load case, as defined in API RP 2RD.

\section{DEVELOPMENT OF THE HP CLIP CONNECTOR}

The Clip connector is a double breech-block type connector with a rotating ring. It was developed for low pressure (5000 psi) marine riser applications during the 1980 s by the IFP and several industrial partners. Reference [9] presents the main features of the Clip connector as noted during record drilling operations in the Mediterranean Sea. The main advantage of this connector is to allow very fast make-up or break-out of the riser sections with a connection which requires just a few seconds to make-up or break-out. Significant cost savings can be obtained through the use of the Clip connector, especially when used in deep water. The Clip connector has been used intensively for the last eight years in offshore Africa and, more recently, in the Gulf of Mexico. Reference [10] provides some evidence that it is a very reliable product. Aker Solutions (AS) has been licensed by the IFP for the manufacturing and commercialization of riser systems using the Clip connector. The IFP and AS have finalized the design, qualification and engineering of both 18-5/8" and 21" Clip connectors.

\subsection{Description}

As with all types of riser coupling, the HP Clip connector must basically offer a means of quickly connecting and disconnecting the riser joints that constitute the riser string, which joins the floating vessel to the wellhead at the seabed.

Design specifications of the HP Clip connector are given below:

- inside diameter: 14";

- maximum operating pressure: $10000 \mathrm{psi}$;

- design load (tension + bending): 2800 kips (1270 t);

- torque: $20 \mathrm{ft}$-kips $(27 \mathrm{kN}-\mathrm{m})$;

- designed fatigue life: 200 years $\left(10 \times T_{w}\right)$.

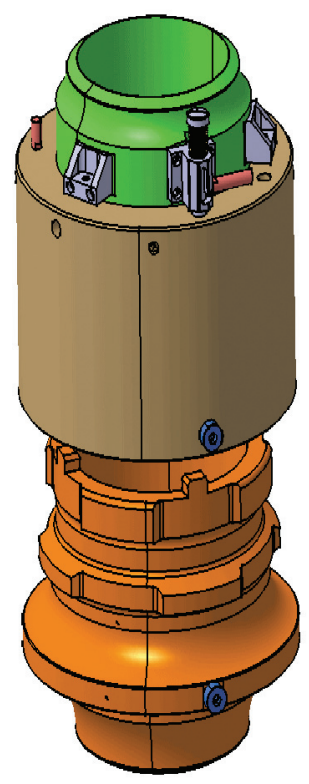

Figure 1

CAD model of the HP Clip connector.

\subsubsection{Materials}

The HP Clip connector (Fig. 1) consists of three massive forged chromium-molybdenum alloy steel parts, described below. The material designation according to AFNOR is 20CNDV10 (yield strength $\approx 93 \mathrm{ksi} \operatorname{mini}(640 \mathrm{MPa})$ ).

\subsubsection{Working Principles}

The HP Clip connector consists of three main parts:

- the female member, which is butt-welded onto the main riser pipe, rests on the spider table during the connection procedure. It has two rows of four circumferential lugs (each of $45^{\circ}$ similar to the 21 " type) on its outside surface that support the tensile and bending loads;

- the male member, which is butt-welded onto the other end of the main riser pipe, supports the rotating ring and has a long stabbing front section;

- the ring rests on the male member; it ensures the link between the male and the female members thanks to the circular bearing and to a set of lugs mating with the corresponding ones on the female member.

\subsubsection{Indexing System}

Due to tight tolerances in the lug imbrication system, indexing of the ring is required during the connector engagement. The indexing system consists of a guiding key fixed onto the ring and a guiding device fixed onto a part independent of the connector such as the spider table or the drill floor. The guiding device may be made up of a circular ferrule with a vertical and a circumferential groove. The key is also guided while inserting the lugs and rotating the ring. 


\subsubsection{Locking System}

A safety device is screwed onto the top of the rotating ring to ensure proper rotation and locking of the ring.

\subsubsection{Torque Resistance}

The connector has been designed for a 20-ft-kips torque. This torque may be caused by the rotation of the rig of $60^{\circ}$ around a vertical axis. The torque loading is supported by means of a system of four crenels and cavities built into the female and the male members.

\subsubsection{Sealing System}

Tightness to internal pressure is provided by a system of two elastomeric seals between the male member and the female member. This dual sealing system allows a field pressure testing procedure through a local port drilled through the female member. The seals are assembled onto the female member in a rod seal configuration. In order to prevent the seals from extrusion, we recommend using spring seal technology.

\subsection{Design}

\subsubsection{Methodology and Standards}

The connector has been designed using the API Spec 16R. This standard describes the rules to be followed for designing drilling riser connectors but it does not take into account the features of high-pressure connectors. API RP 2RD may be used to modulate the allowable stresses with a coefficient, $C_{f}$, depending on the operational situation (Tab. 1).

According to API Spec 16R, five criteria must be satisfied in the riser coupling. These criteria are:

$$
\begin{array}{ll}
S_{p m} & \leq 0.667 \times C_{f} \times S_{y} \\
S_{l m}+S_{p b} & \leq C_{f} \times S_{y} \\
S_{l m}+S_{p b}+S_{s e} & \leq 2 \times C_{f} \times S_{y} \\
S_{s h} & \leq 0.4 \times C_{f} \times S_{y} \\
S_{b r} & \leq C_{f} \times S_{y}
\end{array}
$$

The stresses must be linearized, separated into membrane and bending components, categorized into primary, secondary or peak stresses and converted into equivalent Von Mises stresses before they can be compared with the allowable stresses. API post-processing must be performed in any section of the connector. The section in a $2 \mathrm{D}$ model is defined as a straight line and extends to a plane in a 3D model. Also, a Stress Factor (SF), defined as the maximum ratio between the calculated stresses and the allowable stresses, is calculated in any section.

\subsubsection{Finite Element Analyses}

The finite element analyses were performed with the Systus V.2003 program from ESI Group. Systus is a multiphysics simulation software which covers fields as diverse as civil and mechanical engineering, nuclear power, energy and transportation. It has been certified according to the ISO9001 standard.

\subsubsection{D Finite Element Analysis}

As a first step, the overall design of the HP Clip connector was optimized through 2D axisymmetric finite element analyses. The non-axisymmetry of the lugs of the connector was taken into account through a multiplier coefficient applied to the stresses in the box/ring lug area.

The three parts of the connector were modeled with parabolic axisymmetric elements (triangle or quadrilateral with 6 or 8 nodes) whose size was about $4 \mathrm{~mm}$ everywhere. The model was composed of 15460 nodes and 5320 elements.

The lower end of the female member was fixed in the longitudinal direction. Non-linear contact conditions were applied to the contact surfaces between:

- the female and lock ring lugs;

- the lock ring support onto the male member;

- the male and female members.

The contact was supposed to be sliding. No friction was taken into account in this analysis.

As the result of the riser analysis, the connector was designed for the following loading case which corresponded to extreme conditions:

- tensile load set at 2800 kips was applied on the upper end of the male member;

- 10000 psi local pressure was applied on the internal surfaces of the male and female up to the first seal.

The material behavior was supposed to be elastic. For the purposes of the stress post-processing, the yield strength for the Clip connector material was specified to be at least $640 \mathrm{MPa}$ (93 ksi).

The finite element results were post-processed according to API rules and criteria. Four iterations were required to reach the final sizing.

\subsubsection{D Finite Element Analysis}

Then, in order to take into account the non-axisymmetry of the lugs of the connector, a 3D finite element analysis was performed to validate the optimized design (Fig. 2a, b).

A one-eighth symmetry three-dimensional finite element model of the HP Clip connector with nominal dimensions was developed with Systus and Catia CAD software. The model included a precise definition and a fine meshing of the lugs was composed of 77400 nodes and 18200 parabolic elements with 15 or 20 nodes. The average size of the elements was about $4 \mathrm{~mm}$ in the lug area.

The same hypotheses were defined in the 3D model regarding the boundary and contact conditions, the loading case and the material behavior. In addition, symmetrical boundary conditions were defined in both planes of symmetry of the model. 
a)

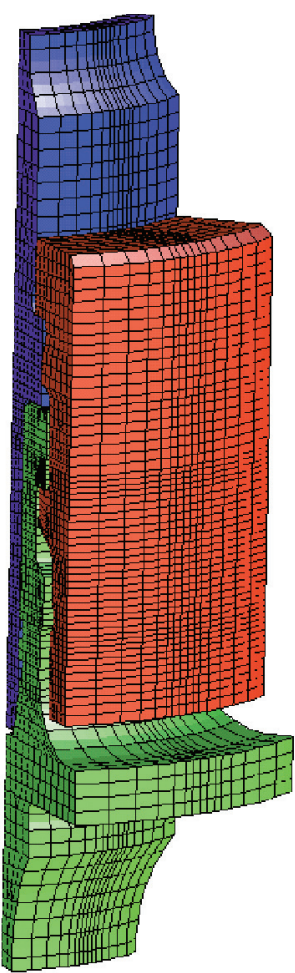

Maximum stress factor according to API criteria was 0.99 , showing a good optimization. The section was located in the upper lug of the female member. API post-processing demonstrated that the connector design properly met the API requirements for stresses.

The FE analysis was of sufficient detail beyond what was normally required for design, so that, once calibrated with the results of the testing, it could be used as a tool to simulate additional load cases using FE analysis instead of testing.

\subsection{Prototype Testing}

A HP Clip connector prototype was supplied by Aker and a qualification testing program was carried out at the IFP (Fig. 3). The test facility used for this program (and for following tests on hybrid riser pipes) is first described.

\subsubsection{Test Facility}

All tests with tension were performed at the IFP on a fatigue test device, which can also be used for static tests. This test device is limited to a maximum traction of 1100 kips (500 tons) in static, and to a maximum traction of 660 kips (300 tons) in dynamic. Traction is applied with a hydraulic cylinder, with a frequency for fatigue tests up to $5 \mathrm{~Hz}$ (Fig. 7, 17). Specimens up to $6 \mathrm{~m}$ in length can be tested with this device.

Figure 2a

3D FEM of the HP Clip connector.
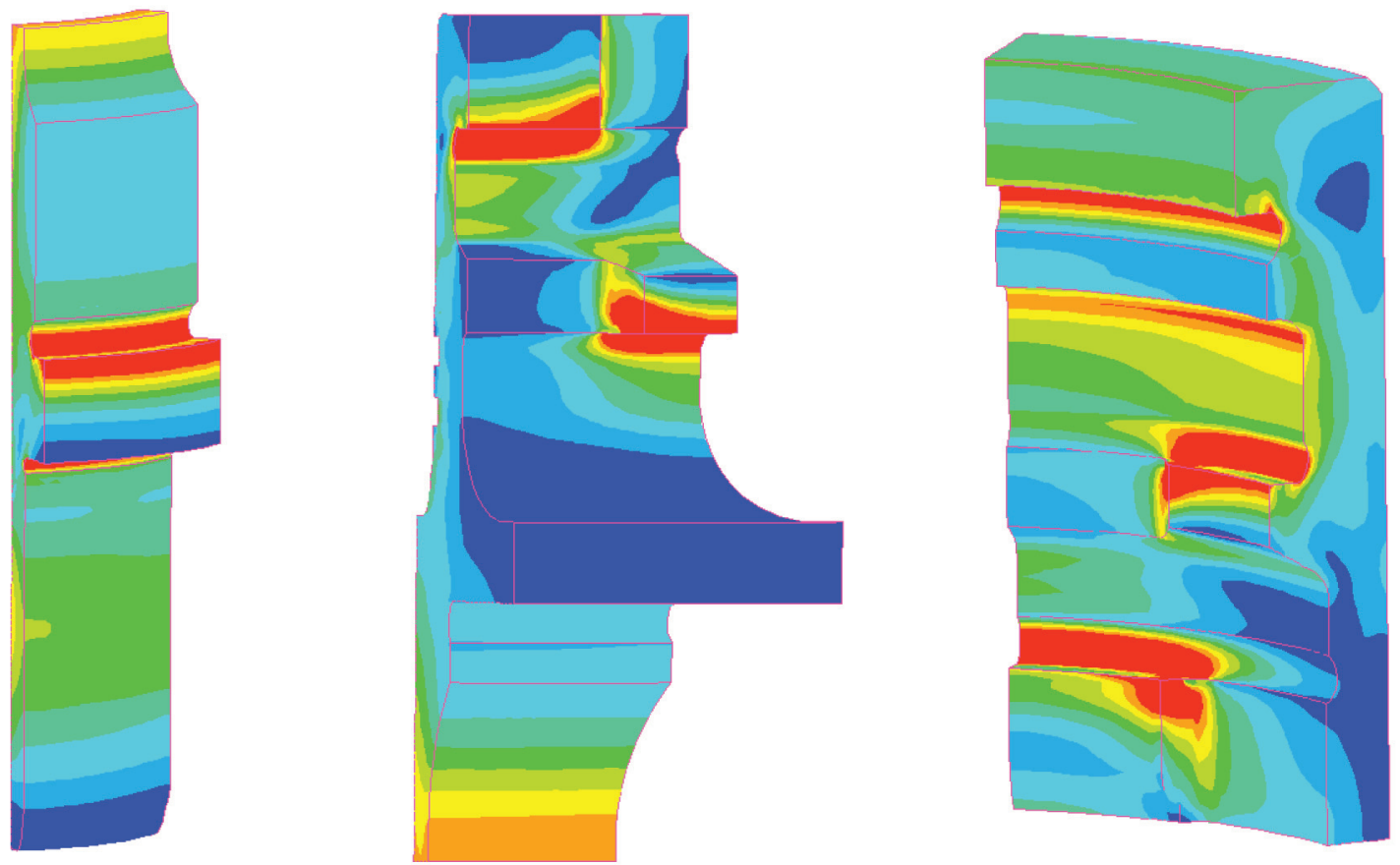

b)

Figure 2b

Von Mises stress iso-values in the HP Clip connector. Areas in red exceed the minimum yield strength. 


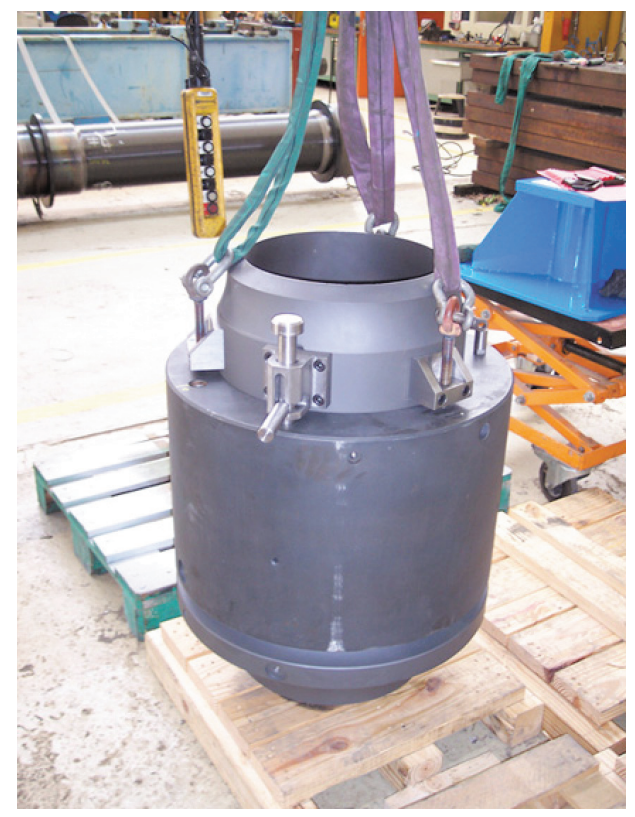

Figure 3

HP Clip connector prototype.

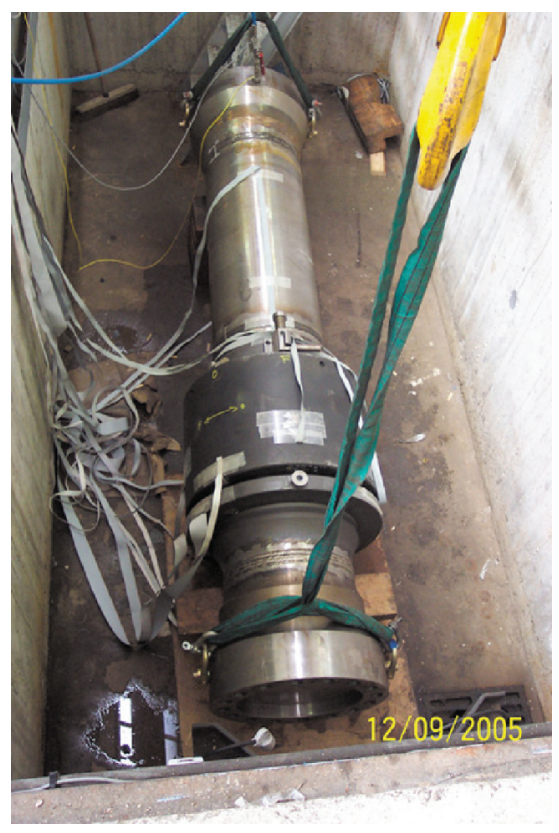

Figure 4

Test assembly o the HP Clip connector.

For internal pressure tests with end caps, but without additional tension, the connector prototype was placed horizontally in a pit (Fig.4).

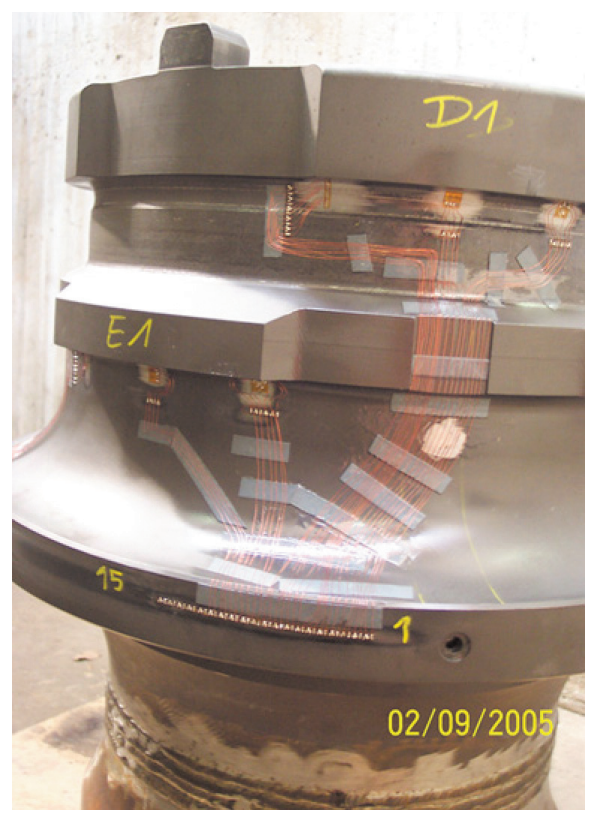

Figure 5

Gage cabling of the female member.

\subsubsection{Sensors}

All sensors were calibrated before the beginning of the tests:

- uncertainty on the pressure is less than 1 bar in the range 0-1500 bar;

- uncertainty on traction (fatigue test device sensor) is less than $1 \%$ in the range $0-1000$ kips.

\subsubsection{Static Tests}

The following static tests were performed:

- a pressure test with water at the maximum operating pressure: 10000 psi (Fig. 4);

- a tensile test at the maximum test fixture capacity: 981 kips (445 t);

- a combined pressure and tension test up to 5800 psi (400 bars) and 981 kips.

A large number of strain gages (about 70 strain channels) including biaxial, rosette and strip gages were bonded onto the highest stress areas of the connector, in particular in the lug area (Fig. 5).

Whatever the test conditions and the location of the strain gages, the comparison between test and simulation showed that the strain measurements were in good agreement with the finite element results, in particular in the lock ring (Fig. 6). In the center of the lower lug of the female member (gage 59), the gap between test and calculation was about $15 \%$. That difference could be explained by the mesh 


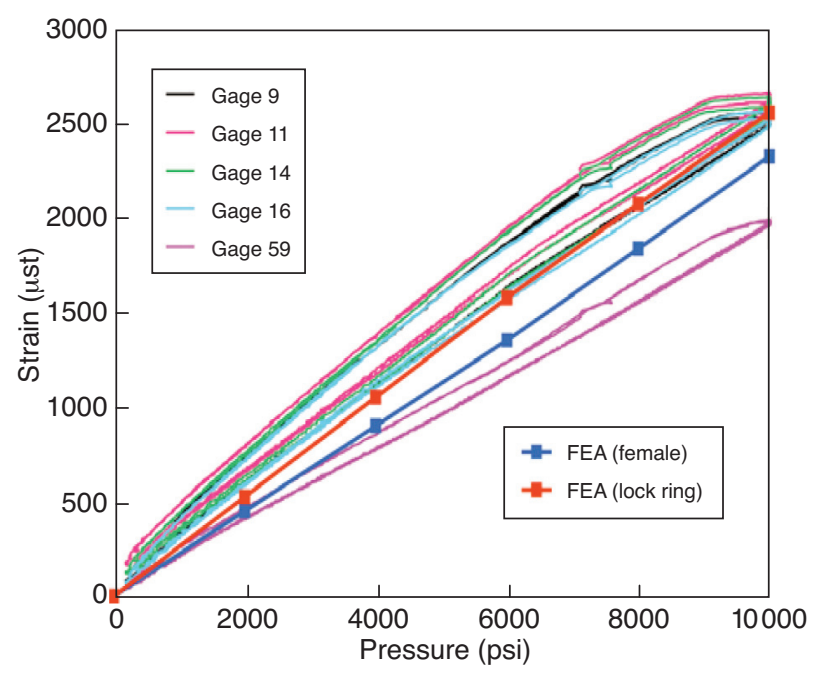

Figure 6

Axial strain measurements $v s$ FEA simulations. Pressure test up to 10000 psi (690 bars).
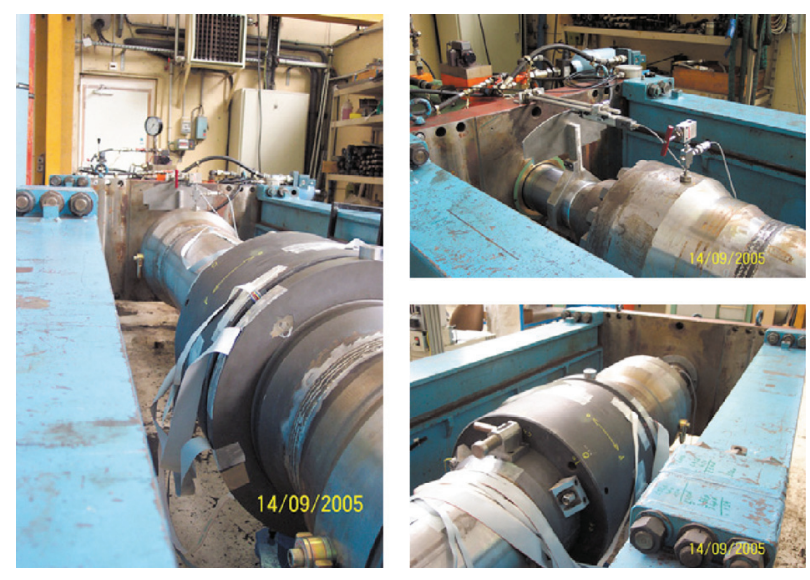

Figure 7

HP Clip connector on the fatigue bench.

discretization of this area, which was not as fine as it was in the lug edge area. A non-linear effect during unloading can also be noted, that could be explained by the seal behavior. Indeed, in the first step of depressurization, from $10000 \mathrm{psi}$ down to 9000 psi, axial strain remains almost constant. Pressure decrease is balanced by the seal tightening. In the second step, the seals are released and axial strain decreases down to 0 .

\subsubsection{Fatigue Testing}

Two series of fatigue tests were performed in conditions much more severe than the normal working conditions of the HP Clip connector (Fig. 7).
A first fatigue test was performed under the following conditions:

- internal pressure of 6672 psi (460 bar);

- dynamic tensile load of $287 \pm 165$ kips $(130 \mathrm{t} \pm 75 \mathrm{t})$;

$-5 \times 10^{6}$ cycles with a frequency of $4 \mathrm{~Hz}$.

For the fatigue test, 28 axial strain gages were used and monitored during the test. In addition to the strain measurements, other sensors were used to measure tension, pressure and displacement of the hydraulic jack. Numerous data were recorded.

Five million cycles were successfully performed.

Then, a second fatigue test was performed with higher load variations that created more severe fatigue conditions in the lug area:

- near constant internal pressure of 4350 psi (300 bar);

- dynamic tensile load of 330 kips \pm 200 kips (150 t $\pm 90 \mathrm{t}$ ).

Three million cycles were successfully performed without significant variation in the measured strains (Fig. 8). Note that the sudden drops in Figure $8 \mathrm{~b}$ are due to internal pressure adjustments, as internal pressure varied with the ambient and prototype temperatures.

\subsubsection{Resistance Testing}

A Load Rating Test (LRT) was performed to the maximum design capacity: 10000 psi and 981 kips simultaneously.

In addition, a pressure test at 1.5 times the maximum operating pressure (15000 psi or 1034 bars) was performed on the HP Clip connector after fatigue testing without damage or leakage. This test was aimed at evaluating the safety margin of the connector before failure as well as the ability of the seals to operate at high pressure.

\subsubsection{Seal Material Testing}

Seals from two manufacturers were tested in a special cell according to the following protocol: increase pressure in 10 steps to 10000 psi (690 bars) with water, then with gas, then with the maximal extrusion gap, and then pressure increase to 14500 psi (1000 bars). Both seals were tested successfully without leakage or degradation.

\subsubsection{Make and Break Testing}

Ten successive make-up sequences were carried out to simulate the full make-up and break-out of the HP Clip connector on the drill floor and its repeatability. A pressure test to 15000 psi (1034 bars) was performed to test the sealing system after each make-up sequence. In addition, a few connections of the HP Clip connector were successfully achieved with a $10^{\circ}$ angular misalignment of the male and the female members.

Make and break tests demonstrated the ability of the HP Clip connector to be easily and quickly made up in the field and the repeatability of the make-up and break-out without damage. 


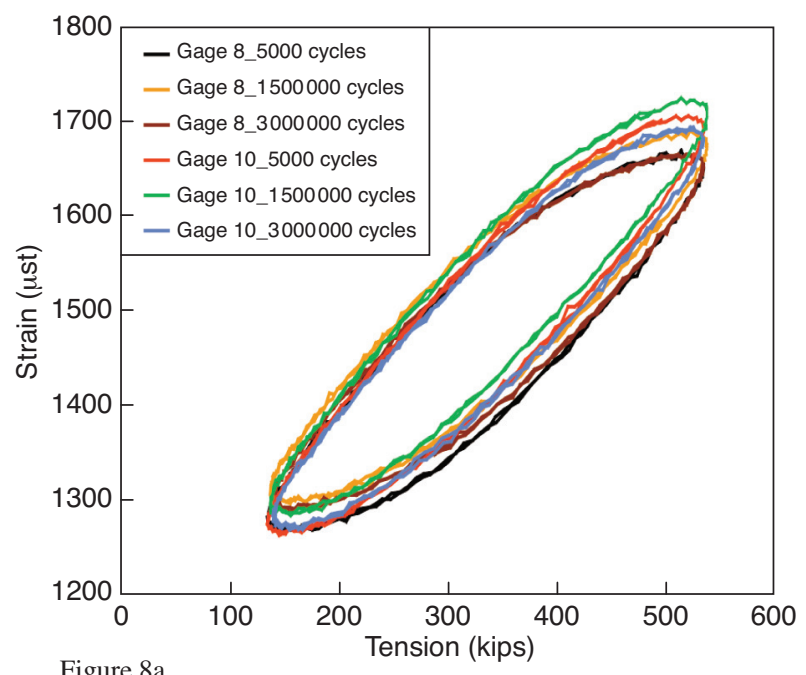

Figure 8a

Fatigue testing results of the HP Clip connector. Axial strain variation $v s$ tension.

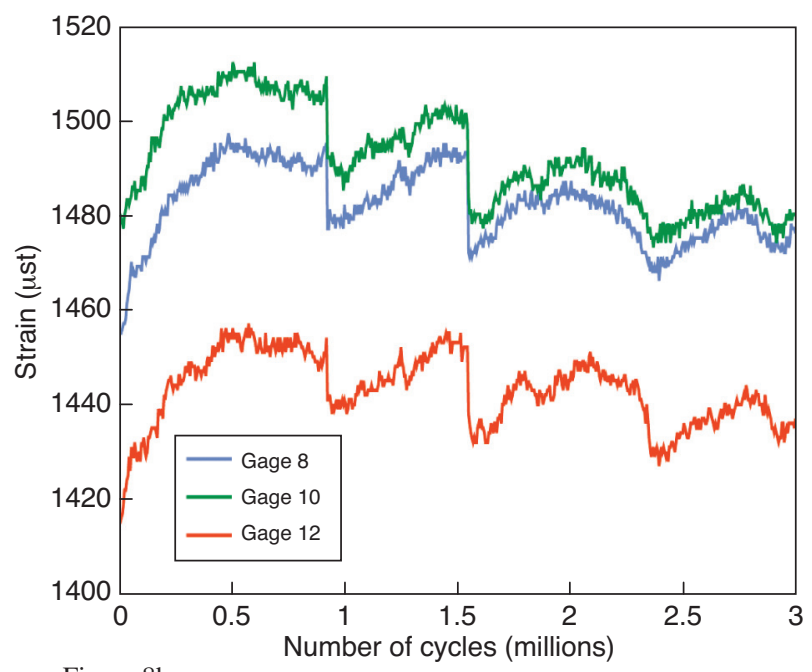

Figure $8 b$

Fatigue testing results of the HP Clip connector. Mean axial strain $v s$ number of cycles.

\subsubsection{Final Inspection}

A visual inspection of the HP Clip connector was performed after the testing program in order to describe and explain all the visible marks on the connector. Among all the marked areas, two different types of minor marks were noticed:

- some were caused by the seal spring pressing onto the connector;

- the other ones were caused by friction between the male and the female members at the stabbing area level.

Other than these minor marks, neither degradation nor damage was noticed. However, in order to avoid the marks caused by the friction, a special hardening treatment was recommended for the external surface of the male member opposite to the female member.

A dye penetrant inspection of the stress relieves below the lugs of the female member did not show any evidence of cracks or degradation in the highest stressed parts of the connector after the fatigue tests.

\subsection{Working Diagram}

Figure 9 illustrates the working diagram of the HP Clip connector. Based on the FEA model, the blue line shows the working limits of the Clip connector for combined pressure and tension loads. The squares represent the various testing conditions used for the qualification of the prototype.

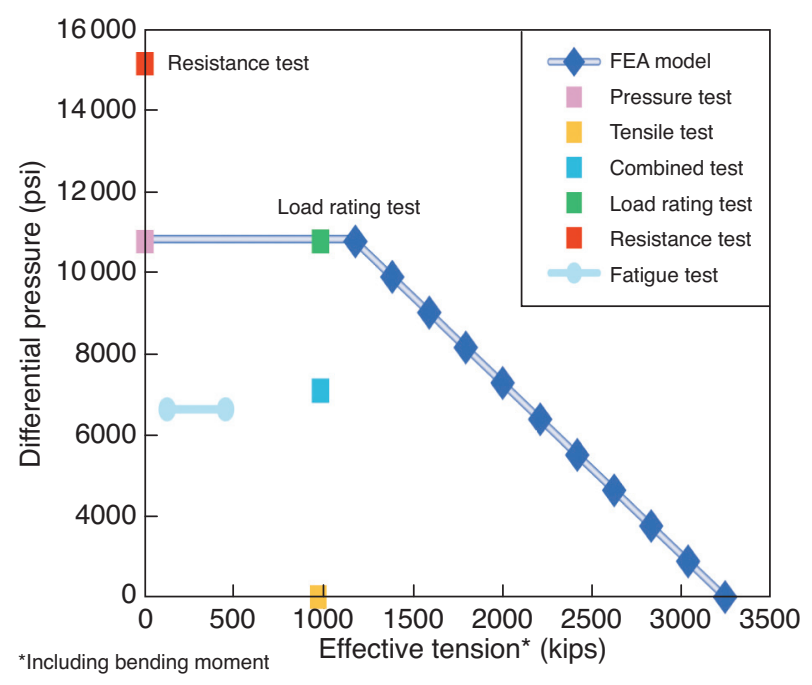

Figure 9

Working diagram of the HP Clip connector.

\subsection{Conclusion for the Development of the HP Clip Connector}

After carrying out design studies through CAD and extensive FEA, a complete testing program including static tests to verify stress distribution, a load rating test, a fatigue test, and resistance and seal tests was performed on a HP Clip connector prototype. The main results are listed below:

- static tests verified the stress distribution in the highest stress areas of the connector and validated the finite element model of the HP Clip connector. Strain measurements made under tension and internal pressure tests were in good agreement with the FEM results;

- good validation of the FE model was obtained;

- fatigue and load rating tests demonstrate that the HP Clip connector was able to withstand high operating and severe storm conditions without damage; 
- the seals were qualified to operate at high pressure up to 15000 psi (1034 bars);

- a resistance test at pressure of 15000 psi provided confidence in the HP Clip connector technology;

- make and break tests demonstrated the ability of the connector to be easily and quickly made up in the field and the repeatability of the make-up and break-out without damage.

In conclusion, the main results confirmed that the HP Clip connector is well suited for ultra-deep offshore drilling.

\section{DEVELOPMENT OF THE HYBRID RISER PIPE}

In order to resist the high internal pressure, an all-steel riser design would lead to thick and heavy riser pipes that would require a high tensioning capacity. Such a solution would thus restrict the use of existing rigs in much deeper water depths.

By using the hybrid technology developed by the IFP, significant weight savings have been achieved and make it possible to design an effective riser system to withstand the high pressure and deep water requirements.

\subsection{Hoop-Wound Pipes}

\subsubsection{Description of the Technology}

The technology presented in this section is designed to reduce riser mass by replacing the heavy steel pipe by lighter pipes. This is achieved by using hybrid pipes composed of a steel pipe hoop-wound with a carbon/polyamide thermoplastic tape.

\subsubsection{Working Principles}

The working principle of the hybrid pipes is quite simple (Fig. 10). The composite carbon tape provides a pre-stress in the steel core. During the initial pressure build-up, the steel core resists the induced load until the hoop stresses in the steel reach the yield strength. For instance, if an internal pressure of at least $14500 \mathrm{psi}$ (1000 bars) is required before this occurs, then any further increase in the internal pressure will be mainly withstood by the composite hoop winding. The fibers work under tensile forces due to circumferential winding. When hoop stresses are much higher than axial stresses (in other words, when the riser design is governed by internal pressure rather than axial tension, which is the case for the present SBOP riser), failure of the hybrid pipe first occurs when the fibers of the composite tape break.

\subsubsection{Application to Choke \& Kill Lines for Conventional Riser}

The hybrid pipe technology proposed for the high-pressure riser pipe is derived from the technology previously developed for choke \& kill lines. Reference [11] presents the hybrid pipe technology and the qualification testing performed at the
IFP. Reference [12] reports the results of a 5-year field test of hybrid choke \& kill lines. The 4.5 ID hybrid choke \& kill lines have to withstand high internal service pressures up to $15000 \mathrm{psi}$, according to the BOP series, as well as the axial loads depending on the integration method. Such lines would normally require a 1 -inch or more wall thickness. However, by using carbon fiber polyamide tape, hoop-wound around the steel core, the steel wall thickness can be reduced to about $1 / 2$ ". Detailed descriptions of the application of hybrid pipe technology to choke and kill lines are given in [11] and [12].

\subsubsection{Specifications for the Riser Pipe}

Design specifications of the HP riser pipe were based on the following:

- geographical area: Gulf of Mexico;

- water depth: $10000 \mathrm{ft}$ (3048 m);

- maximum operating pressure (test and well control): 10000 psi (690 bars);

- minimum inside diameter: 14";

- maximum mud density: 13 ppg;

- maximum vessel-rated top tension 1280 kips (1000 kips at riser top).

\subsection{Design of the Prototype Hybrid Riser Pipe for Testing}

Pursuant to the design study, a prototype assembly consisting of two hybrid riser pipe sections with a HP Clip connector was considered. The prototype should have been representative of the hybrid pipes designed according to the basic specifications. However, because the selected pipe and the connector prototype were not available on time for testing purposes, it was decided to use an available pipe with reduced specifications

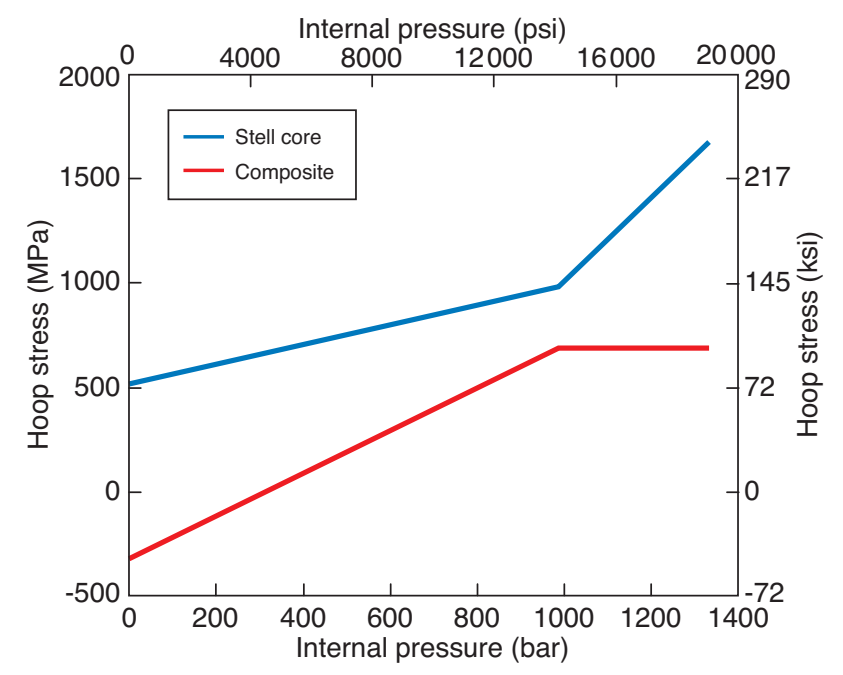

Figure 10

Working principle of hybrid pipe. 
and a dummy connector made of similar material to the HP Clip connector.

The design study of the hybrid riser pipe was thus revised on the basis of the available pipe and materials in order to apply similar stresses in both the steel and the composite sections.

\subsubsection{Pipe Specification}

- outside diameter: 16" (406.4 mm);

- steel wall thickness: 0.57" (14.6 mm).

\subsubsection{Materials}

- the steel grade of the pipe was API 5CT N80 Q-HC;

- the steel grade of the dummy connector was ASTM A182 F22 with the same characteristics as the material of the HP Clip connector (AFNOR 20CNDV10).

The composite material, in the form of composite tape, was made of carbon fibers (50\% volume) embedded in thermoplastic resin (polyamide 12). The composite tape had the following mechanical properties:

- young modulus: $E_{l}=15 \mathrm{Mpsi}(105000 \mathrm{MPa})$ in the fiber direction;

- tensile strength: $S_{u}=246 \mathrm{ksi}(1700 \mathrm{MPa})$.

\subsubsection{Design Criteria}

\section{Steel}

According to the API RP 16Q and API RP 2RD, the following criterion must be satisfied in the steel core of the hybrid pipe:

$$
\sigma_{V M} \leq 0.667 \times C_{f} \times S_{y}
$$

The same criterion was retained for the steel part of the transition region in the hybrid pipe.

\section{Composite material}

Based on the manufacturing company's (Composites Aquitaine) experience with composite material design, we assumed that the circumferential stresses would not exceed $40 \%$ of the ultimate strength of the carbon fibers (to be modulated by the coefficient $C_{f}$ as shown in Tab. 1):

$$
\sigma_{C C} \leq 0.4 \times C_{f} \times S_{u}
$$

TABLE 2

\begin{tabular}{c|c|c}
\hline Operating conditions & Steel & Composite \\
\hline Drilling & $\sigma_{V M} \leq 66.7 \% \times S_{y}$ & $\sigma_{C C} \leq 40 \% \times S_{u}$ \\
\hline Well control & $\sigma_{V M} \leq 80 \% \times S_{y}$ & $\sigma_{C C} \leq 48 \% \times S_{u}$ \\
\hline Pressure testing & $\sigma_{V M} \leq 90 \% \times S_{y}$ & $\sigma_{C C} \leq 54 \% \times S_{u}$ \\
\hline
\end{tabular}

\subsubsection{Design Loads}

Seven operating cases were taken into account for the design of the riser (Tab. 1).

A computer program has been developed by the IFP to design the main part of hybrid riser pipes under different conditions of pressure (internal, external), axial loads and temperature. The results are given in Table 3 in percentage of yield for the steel core and in percentage of the ultimate strength for the composite tape in the last line. In order to verify that the pipe will meet the criteria for stresses in the transition section, a stress amplification factor of 1.07 was applied.

TABLE 3

Operating envelope of the hybrid riser pipe for testing

\begin{tabular}{c|c|c|c|c|c|c|c|c|c|c}
\hline \multicolumn{2}{c|}{ Diff. pressure } & $0 \mathrm{psi}$ & 1450 & 2900 & 4350 & 5800 & 7250 & 8700 & $10150 \mathrm{psi}$ & $11600 \mathrm{psi}$ \\
\hline \multicolumn{2}{c|}{ Eff. tension } & 0 bar & 100 & 200 & 300 & 400 & 500 & 600 & 700 & 800 \\
\hline 0 kips & 0 ton & $41 \%$ & $32 \%$ & $27 \%$ & $28 \%$ & $34 \%$ & $43 \%$ & $54 \%$ & $66 \%$ & $78 \%$ \\
\hline 220 & 100 & $45 \%$ & $38 \%$ & $34 \%$ & $35 \%$ & $40 \%$ & $49 \%$ & $59 \%$ & $70 \%$ & $82 \%$ \\
\hline 440 & 200 & $50 \%$ & $44 \%$ & $41 \%$ & $42 \%$ & $47 \%$ & $55 \%$ & $64 \%$ & $75 \%$ & $86 \%$ \\
\hline 660 & 300 & $55 \%$ & $50 \%$ & $48 \%$ & $50 \%$ & $54 \%$ & $61 \%$ & $70 \%$ & $80 \%$ & $91 \%$ \\
\hline 880 & 400 & $61 \%$ & $57 \%$ & $55 \%$ & $57 \%$ & $61 \%$ & $68 \%$ & $76 \%$ & $86 \%$ & $96 \%$ \\
\hline 1100 & 500 & $67 \%$ & $64 \%$ & $63 \%$ & $64 \%$ & $69 \%$ & $75 \%$ & $83 \%$ & $92 \%$ & $102 \%$ \\
\hline 1325 & 600 & $74 \%$ & $71 \%$ & $70 \%$ & $72 \%$ & $76 \%$ & $82 \%$ & $89 \%$ & $98 \%$ & $107 \%$ \\
\hline \multicolumn{2}{c|}{ in composite } & $26 \%$ & $29 \%$ & $32 \%$ & $35 \%$ & $37 \%$ & $40 \%$ & $43 \%$ & $46 \%$ & $49 \%$ \\
\hline
\end{tabular}

\begin{tabular}{|c|c|c|c|c|}
\hline Type of operation allowed & Drilling & Control & Testing & None \\
\hline Steel main part (\% of yield) & $0-62 \%$ & $62-75 \%$ & $75-84 \%$ & $>84 \%$ \\
\hline Steel transition part (\% of yield) & $0-67 \%$ & $67-80 \%$ & $80-90 \%$ & $>90 \%$ \\
\hline Composite (\% of strength) & $0-40 \%$ & $40-48 \%$ & $48-54 \%$ & $>54 \%$ \\
\hline
\end{tabular}

Code of colors 
As a result of the analyses, the design load for the design of the transition section was set to:

- maximum operating pressure: 10000 psi (690 bar);

- tensile load: 440 kips (200 tons).

\subsubsection{Manufacturing Process}

The manufacturing process consists of winding multiple layers of composite tape around the steel pipe. The pipe rotates around its axis and a winding arm moving parallel to the pipe carefully applies a well-controlled tension to the composite tape. The tape is locally melted using a small blowtorch and the adjacent layers are fused together to create a solid layer around the steel core (Fig. 11).

\subsubsection{Transition Section}

As usual for drilling risers, the connector pieces (male and female members) are welded onto the ends of the steel pipe. In the case of a hybrid pipe, the design of the transition section (tapered section) from the hybrid pipe to the end connectors requires special attention as it also contains the termination of the composite hoop wraps. The pipe-toconnector welds are made first. Then the welds are ground (planed down) to constitute a cylindrical assembly. The composite layers are then laid down covering the weld until they reach the tapered ends of the connector. Some additional layers may be required to allow a good transition of stresses and deformations between the pipe and the connector.

The design of the transition section is of prime importance as it may be the leak point of the riser joint. Its design was determined by using the finite element method.

\subsubsection{Finite Element Analyses}

The finite element analyses were performed with the Systus V.2004 program from ESI Group.
Due to the near $90^{\circ}$ winding angle of composite layers around the steel pipe, an axisymmetric finite element model is sufficient to precisely capture the real test model. Therefore, two-dimensional models, including the pipe, the dummy connector and all the layers of the composite hoop, were used to validate and optimize the design of the transition of the pipe to the Clip connector.

The transition section was modeled with parabolic axisymmetric elements (triangle or quadrilateral with 6 or 8 nodes) whose size was about $5 \mathrm{~mm}$ everywhere.

The lower end of the pipe was fixed in the longitudinal direction. The materials were supposed to be elastic. An orthotropic behavior law was considered for the composite material.

The transition section was designed for the following loading cases:

- manufacturing process;

- maximum operating pressure: 10000 psi (690 bar);

- tensile load: 440 kips (200 tons).

These models allowed precise simulations of the composite hoop-winding process as well as the behavior of the riser pipe under the combined effects of pressure and tension. Regarding the composite design, several winding processes were studied by varying the number of layers and tension in the layers.

Finite element analyses demonstrated that the design study of the transition area may be divided into two separate problems. The axial stress governs the design of the transition geometry in steel, whereas the composite winding process leads to the definition of the composite overlayers. For the hybrid riser considered in this study, optimization of the transition section through FEA showed that no additional layer was needed in the transition section (Fig. 12).

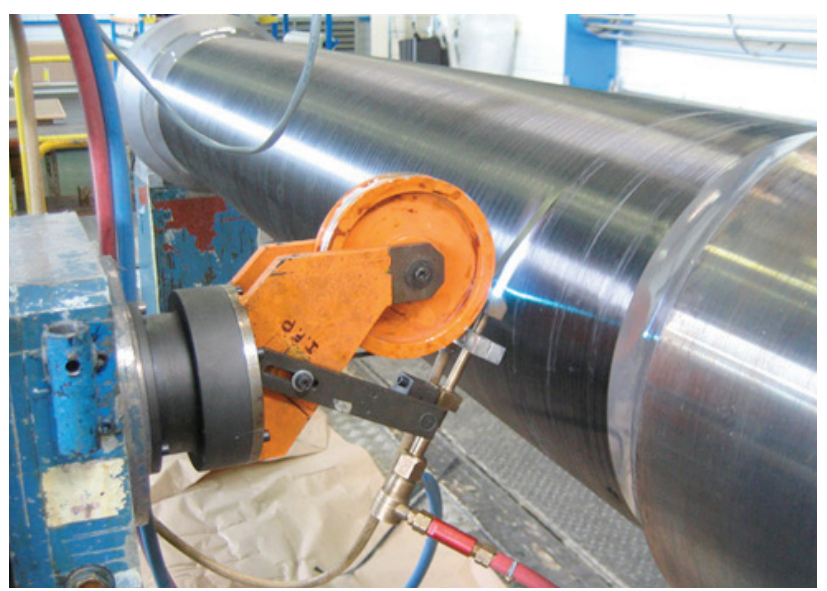

Figure 11

Hybrid pipe during manufacturing process.

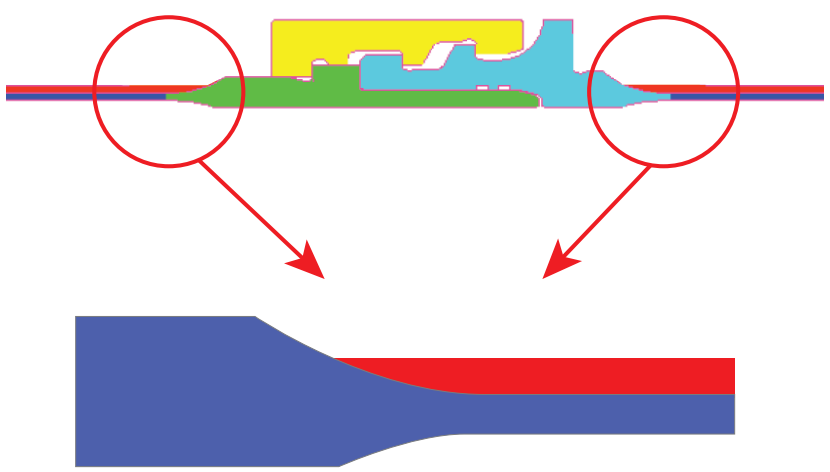

Figure 12

Design of the transition section from hybrid pipe to the end connectors. 


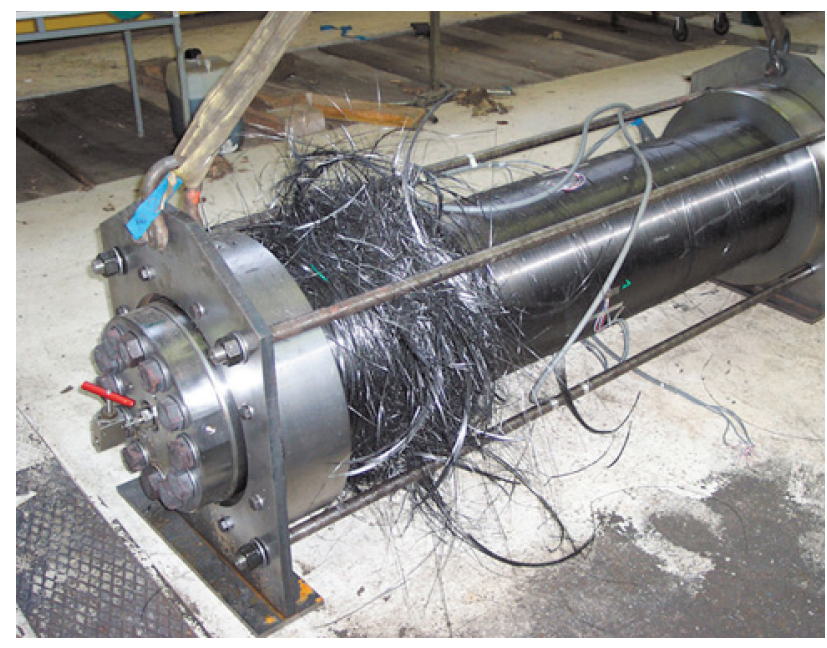

Figure 13

Burst test of a hybrid pipe

$P_{\text {burst }}=22335$ psi (1540 bars).

\subsubsection{Final Design and Properties of the Tested Hybrid Riser Pipe}

The main dimensions of the hybrid pipe were:

\section{Steel pipe:}

- outside diameter: 16" (406.4 mm);

- steel wall thickness: 0.57" (14.6 mm).

Composite hoop wrap (pipe body + transition section):

- number of composite layers: 36;

- composite thickness: 0.43 " (10.8 mm);

- pre-stress in steel core: $39 \mathrm{ksi}(270 \mathrm{MPa})$.

\subsection{Hybrid Riser Pipe Testing}

\subsubsection{Testing Principles}

A testing program was carried out at the IFP to qualify the application of the hybrid pipe technology to high-pressure drilling risers.

Static and dynamic (fatigue) tensile tests were performed at the IFP on the same device as the one used for the connector.

Burst tests of hybrid pipes were performed without the end-pressure effect, using a large mandrel placed inside the hybrid tube. Steel collars were previously placed at the end of the tube to prevent burst at these locations.

Outer composite temperature was obtained by flowing a regulated hot water in a steel cylinder encircling the hybrid pipes.

Collapse tests were performed at the IFREMER (Brest, France) using a hyperbaric testing tank of $2 \mathrm{~m}$ in height and $1 \mathrm{~m}$ in diameter, with a maximum pressure of 14504 psi (1000 bar).

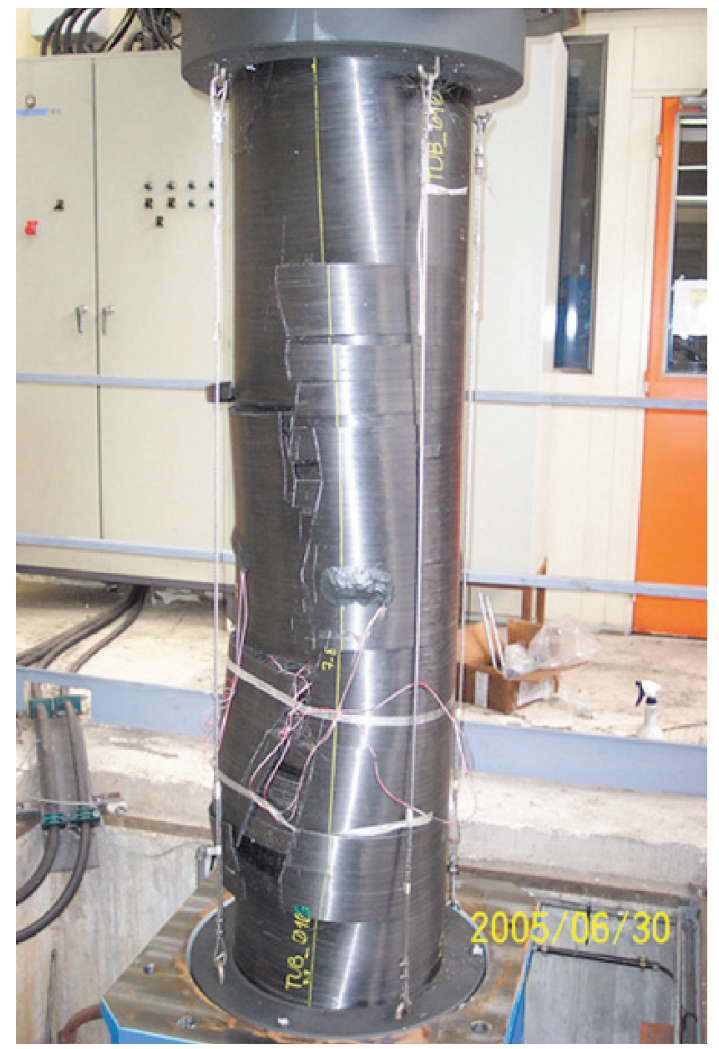

Figure 14

Collapse test of a hybrid pipe

$P_{\text {collapse }}=6527 \mathrm{psi}(450$ bars $)$

\subsubsection{Reference Tests (Burst and Collapse)}

Two 6.5-ft (2-m) long sections of hybrid riser pipe were manufactured by Composites Aquitaine near Bordeaux, France, according to the definition derived from the design study.

\section{Burst Test (Fig. 13)}

A pressure test of the first hybrid pipe section up to the burst (characterized by the break of the fibers) was performed without the end-pressure effect. The burst pressure was 22335 psi (1540 bars), slightly over the predicted value of 20305 psi (1400 bars).

\section{Collapse Test (Fig. 14)}

An external pressure test of the other hybrid pipe section up to the collapse was performed at the IFREMER. The collapse pressure was 6527 psi (450 bars), slightly over the predicted value of $6090 \mathrm{psi}$ (420 bars).

\subsubsection{Prototype Riser Pipe Assembly}

A prototype assembly, consisting of two sections of hybrid riser pipe separated by a dummy connector, was manufactured and tested (Fig. 15). The French Welding Institute (IS) 


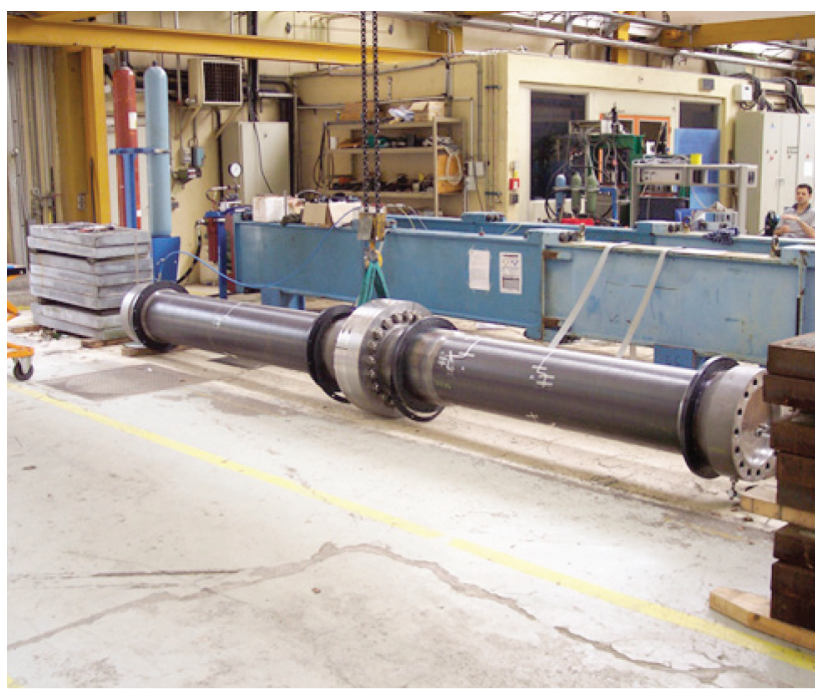

Figure 15

Hybrid riser prototype assembly.

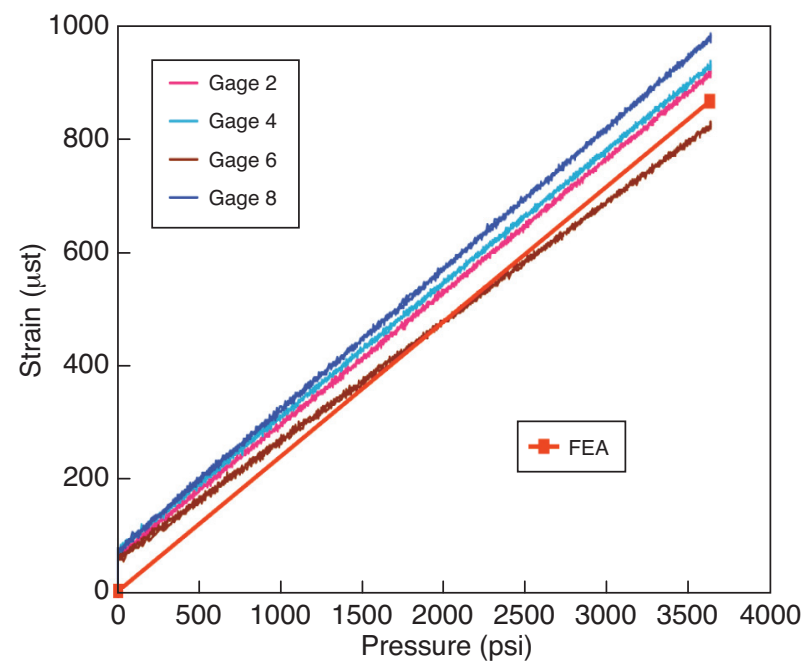

Figure 16

Axial strain measurements $v s$ FEA simulations. Pressure test up to 3600 psi (250 bars).

developed a procedure for welding the pipe onto the connector. Butt-joint welded samples were prepared, machined and tested. The welded samples endured at least 4.5 million cycles at a fatigue loading of $46.7 \pm 9 \mathrm{ksi}(322 \pm 62 \mathrm{MPa})$. Testing results were in accordance with standard $\mathrm{S}-\mathrm{N}$ curves such as API X'.

Welds of the prototype assembly were made according to the welding procedure established by the IS and were controlled by means of $\gamma$-ray examination. No out-oftolerance defects were detected in the welds before starting the tests.

\subsubsection{Static Testing}

The prototype assembly was instrumented with biaxial strain gages in the main part of the pipe sections and in the transition sections (28 gages), in order to verify the design calculation. The strain gages were bonded onto the composite overwrap.

Verification tests consisted of various combinations of internal pressure (up to $10000 \mathrm{psi}$ ) and tension (up to $660 \mathrm{kips}$ ). The following static tests were performed:

- a pressure test at the maximum operating pressure: $10000 \mathrm{psi}$ (690 bars);

- a tensile test at 660 kips (300 tons);

- a combined pressure and tension test up to 5800 psi and 660 kips.

Comparison between the static strain measurements and the finite element calculations showed that:

- the hoop strain measurements were in good agreement with FEA simulations. For the significant strains, the difference between tests and simulations was always lower than $15 \%$ (Fig. 16). That difference could be explained by the initial state of the hybrid tube, which is not perfect. Especially, discrepancy between strain gage measurements (Fig. 16) is not surprising;

- a large dispersion of measured axial strains was observed. Significant differences between test results and FEA simulations were observed.

As the composite hoop wraps were not designed to withstand axial load, it was difficult to get realistic axial strain measurements from the strain gages on composite overwraps. Hence, poor agreement in predicted and measured axial strains was not a surprise.

\subsubsection{Fatigue Testing}

The prototype assembly was tested in the following fatigue conditions (Fig. 17):

- internal pressure of 6672 psi (460 bar);

- dynamic tensile load of $287 \pm 165$ kips (130 t $\pm 75 \mathrm{t}$ );

- outer composite temperature: $70^{\circ} \mathrm{C}$;

$-5 \times 10^{6}$ cycles were planned.

Although five million cycles were planned, the fatigue testing was interrupted after 450000 cycles due to failure in a weld of the assembly.

\subsubsection{Welding Problem and Discussion}

A close examination of welded joints extracted from the failed pipe, including macroscopic and microscopic examinations such as metallographic and fractographic evaluation, was carried out by the Welding Institute (IS). Examination of the welded joint fracture revealed a 26-mm-long through-wall crack and a very oxidized surface, $19 \mathrm{~mm}$ long and $5 \mathrm{~mm}$ deep, suggesting that initial damage had existed before the 


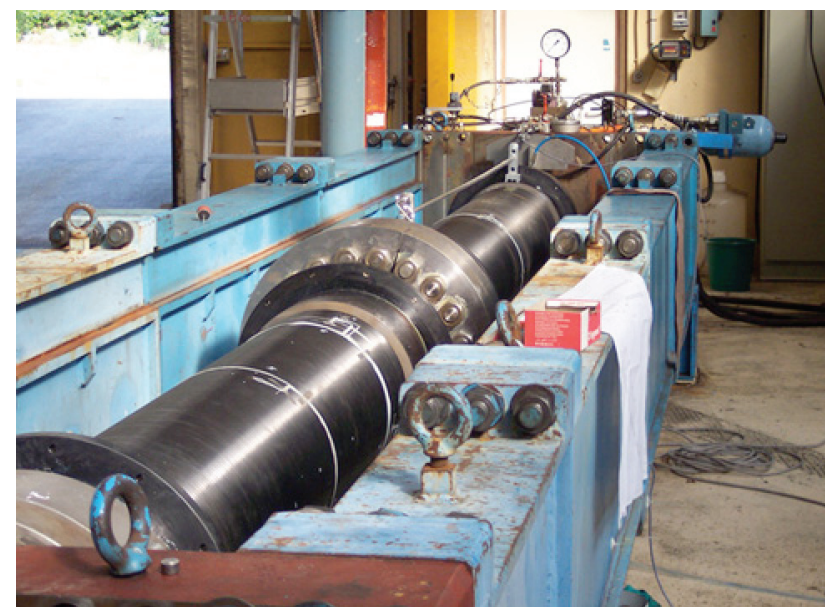

Figure 17

Prototype assembly on the fatigue bench.

tests. The IS concluded that the failure of the welded joint had resulted from a defect that appeared during the welding process, that could be attributed to a cold cracking effect. The IS believed that the specified preheat temperatures were not correctly respected during the welding process.

The tests confirmed the ineffectiveness of radiographic examination in detecting cracks in the weld. No out-oftolerance defects were detected in the welds before starting the tests. The IS's recommendation was to use a combination of radiographic and ultrasonic examinations. The combined use of both techniques would allow detection of this type of defect in the weld. Finally, particular care must be followed in the welding process, strictly respecting the procedure, such as preheat temperatures.

\subsubsection{Final Tests (Burst and Collapse)}

Both sections of the hybrid riser pipe were extracted from the prototype assembly after partial fatigue testing. Two pressure tests (collapse and burst) were performed and compared with the reference test results in order to determine if there was a loss of performance due to fatigue.

\section{Burst Test}

the test sample included a pipe to connector transition. The burst test was carried out in the same manner as the reference test. The test was terminated at $21100 \mathrm{psi}$ (1455 bars) due to a premature leakage in the test fixture. However, breakage of some carbon fibers in the hoop wrap was observed, indicating that the hybrid pipe was close to burst. The burst pressure was comparable with the $22335 \mathrm{psi}$ (1540 bars) burst pressure obtained in the reference test.

\section{Collapse Test}

The collapse test was performed at the IFREMER in the same conditions as the reference test. The collapse pressure was
6670 psi (460 bars) compared with the 6527 psi (450 bars) obtained in the reference test.

\subsection{Conclusion for the Development of the Hybrid Riser Pipe}

After design studies were carried out through CAD and extensive FEA, a testing program including static, burst and collapse tests as well as cyclic fatigue testing was conducted to qualify a 14-inch ID high-pressure hybrid riser pipe. The main results are listed below:

- comparison between static strain measurements and finite element calculations shows that the hoop strain measurements were in quite good agreement with simulations. For the significant strains, the difference between test and simulation was lower than $15 \%$;

- the burst of a section of 16-inch OD hybrid pipe occurred at a pressure greater than 21100 psi (1455 bars) after fatigue testing compared with the 22335 psi (1540 bars) obtained before the fatigue;

- the collapse test performed after fatigue testing showed no degradation in the hybrid pipe performance. The collapse occurred above 6500 psi (450 bars);

- a procedure for welding the $\mathrm{N} 80 \mathrm{Q}-\mathrm{HC}$ steel pipe onto the F22 dummy connector was developed. Fatigue tests performed on butt-joint welded samples were in accordance with standard S-N curves such as the API X' curve;

- the fatigue test performed on a hybrid riser prototype assembly was interrupted after 450000 cycles due to a failure in a weld of the assembly.

Pursuant to this study, a new hybrid riser pipe prototype should be properly manufactured and tested in fatigue conditions in order to complete the qualification of hybrid pipe technology for ultra-deep sea drilling with a surface BOP. Further work to characterize the performance of the transition section is also needed. However, due to lack of budget, such work has not been done to date.

\section{CONCLUSION}

The development work of the High-Pressure Clip Riser for a $10000 \mathrm{ft}$ water depth and 10000 psi pressure for Surface BOP (SBOP) drilling operations was performed through finite element analysis and validated by static and dynamic (fatigue) laboratory testing, paving the way for field applications. The achieved high burst and collapsed pressures for a relatively lightweight riser are particularly promising for deepwater and high-pressure drilling and development from floaters.

Detailed conclusions for the development of the HP Clip connector and the Hybrid Riser pipe are listed in the corresponding sections of the paper. 
The analytical tools have been successfully calibrated and can be used to design high-pressure risers for different applications. The encountered welding issues should not be seen as a major concern, as they can be controlled and managed within known engineering practice at the manufacturing stage of future commercial products.

The riser designed and tested during the course of this study shows that for Surface BOP drilling with a floater, using a lightweight high-pressure riser, in combination with other complementing technologies, will enable a drilling vessel to drill at three times its nominal maximum water depth. Effort is underway to develop a field trial program to demonstrate the benefits of the lightweight high-pressure drilling riser.

\section{ACKNOWLEDGEMENTS}

The authors wish to express their thanks to Shell International Exploration \& Production, Aker Kvarner Subsea and Composites Aquitaine for supporting the project. They are grateful to their colleagues for reviewing the paper.

\section{REFERENCES}

1 Brander G., Magne E., Newman T., Taklo T., Mitchell C. (2004) Drilling in Brazil in $2887 \mathrm{~m}$ Water Depth using a Surface BOP system and a DP Vessel, SPE paper 87113-MS.
2 Guidelines for the use of Surface BOP's from floating MODU's, IADC, 2004.

3 Azancot P., Magne E., Zhang J. (2002) Surface BOP Management System \& Design Guidelines, SPE paper 74531-MS.

4 API RP 16Q (1993) Recommended Practice for Design, Selection, Operation and Maintenance of Marine Drilling Systems, First Edition, Formerly RP2Q and RP2K.

5 API Spec 16R (1997) Specification for Marine Drilling Riser Couplings, First Edition, Formerly API RP 2R.

6 API Spec 2RD (1998) Design of risers for Floating Production Systems (FPSS) and Tension-Leg Platform (TLPS), First Edition.

7 Heurtier J.M., Biolley F., Berhault C. (1998) Fully coupled dynamic analysis of rigid lines, Proceedings of ISOPE 98, Montreal, pp. 246-252.

8 Toumit S. (2009) Diodore and DeepLines software validation report, PRINCIPIA réf. DVA.945.054.01, février 2009.

9 Lepeuvedic J.P., Guesnon J., Soleille L.M. (1984) A fast coupling for a deepwater drilling riser, SPE Paper 13153, 59th Annual Technical Conference and Exhibition of the SPE, Houston, 1984.

10 De Bonnafos O., Guesnon J. (2000) Riser system for $3000 \mathrm{~m}$ water depth - Pride Africa/Pride Angola approach, IADC World Drilling Congress, Paris, 2000.

11 Guesnon J., Gaillard C., Schaeffner P. (2002) Hybrid Tubes for Choke and Kill Lines, Offshore Technology Conference, Houston, 2002.

12 Poirette Y., Guesnon J., Averbuch D., Dupuis D. (2009) Field Testing of Hybrid Choke \& Kill Lines, Offshore Technology Conference, Houston, 2009.

Final manuscript received in June 2009 Published online in November 2009

Copyright (C) 2009 Institut français du pétrole

Permission to make digital or hard copies of part or all of this work for personal or classroom use is granted without fee provided that copies are not made or distributed for profit or commercial advantage and that copies bear this notice and the full citation on the first page. Copyrights for components of this work owned by others than IFP must be honored. Abstracting with credit is permitted. To copy otherwise, to republish, to post on servers, or to redistribute to lists, requires prior specific permission and/or a fee: Request permission from Documentation, Institut français du pétrole, fax. +33147527078 , or revueogst@ifp.fr. 